\title{
Research on the Athlete Growth Evaluation Model
}

\author{
Jiaxin Wang \\ Sports Science College of Qufu Normal University \\ No.57 JingXuan West Road, Qufu 273165, Shandong, China \\ E-mail: wangjiaxin305@163.com
}

Shandong Colleges Human Social Science Research Project: J09WE07

\begin{abstract}
The relevant research on capital and sports has proved that human capital, social capital, psychological capital is important for the athlete growth, the three-dimensional capital of them can be used to measure the value and growth situation of athletes. Based on this theory, the paper establishes the evaluation index system of athlete growth, and uses exponential equation to build the three-dimensional capital model of athlete growth evaluation, then carries on the empirical study to verify the model through factor analysis.
\end{abstract}

Keywords: Athlete, Growth evaluation, Three dimensional capital, Exponential equation, Factor analysis

\section{Introduction}

In the Western Economics, capital refers to the resources that can be used in the physical production and create income. With social progress and development of research, capital connotation expands from material capital to human capital, social capital and psychological capital. With similar nature and supplementary content, human capital, social capital and psychological capital promote for each other, and constitute the individual career capital, which can be objectively measured, invested the development and effectively managed, it has obviously related with the individual career success. Therefore, in the management of human resources, the researchers attempt to construct the talents growth evaluation model, using human capital, social capital, and psychological capital as the variables. And with large quantities of empirical researches it has been proved to be valid.

In our country, the research on athlete growth evaluation has just begun. They paid much more attention on human capital than social capital and psychological capital, the scientific athlete growth evaluation system has not been formed. Therefore, the paper attempts to construct the three dimensional capital model of athlete growth evaluation, and confirm it through empirical study.

\section{Theoretical Basis of the Three-dimensional Capital Model of Athlete Growth Evaluation}

\subsection{Human Capital and Athlete Growth}

In the mid-20th century, human capital theory expanded the connotation of traditional capital from material capital to human capital; moreover, human capital had much greater contribution than physical capital to economic growth. And human capital received more and more attention.

Athlete human capital refers to the input stocks of knowledge, skill and physical ability in the entire sports career and all life which is able to bring benefits now and in the future. It embodies in the sports skill, physical ability, and tactical knowledge and so on. The athlete human capital is formed through investment and training based on the athlete's sports talent. At the same time, the capital can bring about income, enable the investor to obtain certain repayment.

Competitive Sports in fact is a challenge to the limits of human physiology, it specially requests person's physical quality and physical talent, in fact, the majority of athletes enter the sports because of their remarkable physical talent. Based on the good physical quality, through a systematic and scientific training, athletes study professional sports technology, master and enhance the motor skills, then create the outstanding sports achievement. It can be said that for athletes, human capital is the most important components to evaluate athlete growth condition.

\subsection{Social Capital and Athlete Growth}

Social capital can bring incremental intangible assets, as the resources existing in the social relationship structure. Individual relations may make a connection with each kind social joint in the complex social relations, thus provide the foundation of the establishment of good individual relations. Membership may cause the members to 
enjoy a variety of interior resources provided by organization. The social network may enable the members to have the sense of belonging, and collect each kind of social resources. The trusting relationship may make cooperation and transaction of social members easier to achieve, lower the transaction charge, and reduce the transaction cost or the social cost. Many scholars have studied the relations between social capital and individual growth from many aspects, they find that the level of individual social capital has positive correlation with the growth potential and personal values.

Xu Yanhui (2006) found that social capital has certain promoter action to the development of athlete career, social capital plays the role in the athlete development process based on human capital. And, the self-induced social capital displays tremendous influence on "improving the result", "obtaining the opportunity to display the individual talent". Therefore, social capital is also an important indicator of the athlete growth.

\subsection{Psychological Capital and Athlete Growth}

The concept of psychological capital first appeared in the economics, investment and sociology literatures. From the perspective of positive psychology and positive organizational behavior, Luthans defined it as: the individual positive psychological state, self-efficacy, hope, optimism and resilience are the four typical elements, it goes beyond human capital and social capital, and individual can obtain the competition superiority through the cultivation and development of it. The researchers found that human capital and social capital are only the potential of the realization of organization high-performance, psychological capital is the tool which makes the potential into reality.

In the book "Psychological capital: Developing the human competitive edge", Luthans pointed out that competitive sports should be the important application areas of psychological capital. Many foreign scholars agreed that self-confidence has correlation with operation results. in 1982, Morelli and Martin found at the scene, the more stronger self-efficacy, the more athletes played better in track and field, tennis, diving, gymnastics and other sports. In 1993, Jones and Hardy tested the CSAT-2 revised edition on swimmer: one group with the good competition result and the other with the bad competition result. The results showed that the outstanding swimmers had higher self-confidence. Tian Maijiu and Wu Fuquan discovered through the personality test and the appraisal: one main personality characteristics of partial world champions and world record inventors in our country was self-confident. The characteristic had close correlation with sports result. Compared with the ordinary athletes, the top athletes had the more positive psychological features generally. In the aspect of skills influencing, for low and intermediate athletes, psychological factor accounted for $20 \%$, the physical factor accounted for $80 \%$; But for top athlete just the opposite, the psychological factor accounted for $80 \%$, the physical factor accounted for $20 \%$.

Obviously, the relevant studies have shown the importance of human capital, social capital, psychological capital to athletes growth, and the three capital can be objectively measured, invested development and utilization, therefore, human capital, social capital, psychological capital should be used in scientific measurement of the athlete growth status. They are the theoretical basis of the three-dimensional capital model of athlete growth evaluation.

\section{The Construction of Three-dimensional Capital Model of Athlete Growth Evaluation}

\subsection{Index System of Athlete Growth Evaluation}

In this study, many mature and reliable research results of human capital, social capital and psychological capital are drawing on. The evaluation index system is also set based on the athletes career characteristics.

Human capital is the knowledge, skill, experience and other abilities embodied in person. For athletes, the human capital includes three secondary indicators: knowledge, sports skill, competition experience.

Social capital carries on the survey from structure, relation and cognition three dimensions, the structural dimension contains network density and interactive strength, the relational dimension mainly weighs by the trust level, cognitive dimension contains common language and common prospect, five secondary indicators in total.

The paper adopts the conclusions of Luthans and Youssef, the four indicators of psychological capital are the self-efficacy, hope, optimism and resilience.

Thus, human capital, social capital, psychological capital form the first-level indicators of athlete growth evaluation, knowledge, sports skills, game experiences, network density, interactive strength, trust, common language, common prospect, self-efficacy, hope, optimistic, resilience are the twelve second-level indicators. Athlete growth evaluation index system is shown in Figure 1.

\section{Insert Figure 1 Here}




\subsection{The Construction of Three-dimensional Capital Model of Athlete Growth Evaluation}

The value of athletes can be measured by their human capital, social capital and psychological capital. Along with the athletes growing up, the amount of capital is bound to rise. The upgrading of anyone of the three capital can bring the raising of athletes total capital in the athletes growth. Therefore, the situation of athlete growth can be expressed with the quantitative model. The three capitals are the functions.

For further refining study of the athlete growth, according to the above research method, the paper build the index equation of athletes:

$$
\left\{\begin{array}{l}
G t=f(H c, S c, P c) \\
\partial G / \partial H>0 \\
\partial G / \partial S>0 \\
\partial G / \partial P>0
\end{array}\right.
$$

Gt is the athlete growth index, it represents athlete growth status, is the dependent variable. Hc, Sc, Pc are the independent variables. Hc represents athlete's human capital, Sc represents athlete's social capital, Pc represents athlete's psychological capitals. According to ours definition, Gt is the monotonic increasing function.

Likewise, we can separately establish the equation of human capital, social capital, psychological capital, then establish the athlete growth index simultaneous equation as follows:

$$
\begin{aligned}
& G t=f(H c, S c, P c) \\
& H c=f(K n, T e, E x) \\
& S c=f(N d, I s, T r, S m, S u) \\
& P_{c}=f(S e, H o, O p, R e)
\end{aligned}
$$

$\mathrm{Kn}, \mathrm{Te}, \mathrm{Ex}$ are the weight factors of human capital, stands for knowledge, sports skill, competition experience respectively; $\mathrm{Nd}, \mathrm{Is}, \mathrm{Tr}, \mathrm{Sm}, \mathrm{Su}$ are the weight factors of social capital which correspond to network density, interactive intensity, trust level, common language, common prospect; the weight factors of psychological capital $\mathrm{Se}, \mathrm{Ho}, \mathrm{Op}, \mathrm{Re}$, are the respected symbols to self-efficacy, hope, optimism, resilience. The formula (2) not only has pointed out the three dimensional capital structure of athlete growth, but also gave the assessment method of athlete growth status, the measurement and comparison method of athlete growth index.

\section{Model verification}

\subsection{Sample Selection}

Sample survey is the multi-stage stratified sample survey way, from the beginning of June, 2008, researchers carried out the investigation in Jinan, Qingdao, Yantai, Weihai, Weifang, Taian, Jining, Zibo, in total eight cities in Shandong Province. In the investigation, researchers provided 600 questionnaires, 559 valid questionnaires were recovered and effective recovery rate is $93.2 \%$. The sex distribution of samples: men held $63.8 \%$, women $36.2 \%$. The age distribution of samples: $14 \sim 18$-year-old occupied $41.9 \%$, 19 23-year-old 47.3\%, $23 \sim 27$-year-old 8.2\%, and over the age of $272.5 \%$. The education distribution of samples: The elementary school accounted for $3.1 \%$, the junior middle school $23.6 \%$, the high school $28.1 \%$, and universities $45.3 \%$. The household distribution of samples: the provincial capital city, municipal cities and county-level cities, rural areas accounted for $21.5 \%$, $55.7 \%, 13.1 \%, 9.7 \%$ respectively. The occupational distribution of samples: the percent of professional athletes was 40 , sports school students 34.2 , amateur 25.2. The athlete skill levels distribution of samples: master-level accounted for $34.2 \%$, first-level $21.6 \%$, second-level $37.2 \%$. The sports honor distribution of samples: the masters before the eight of world competitions, intercontinental competitions, national competitions, provincial competitions, the city game respectively was $4.0 \%, 5.0 \%, 46.4 \%, 56.2 \%, 54.2 \%$. Sample sports items included basketball, track and field, handball, weightlifting, judo, taekwondo, shooting, archery and so on. After the input and summary of all questionnaires, software SPSS16 was used to the processing statistical analysis. 


\subsection{Measuring Tool}

Variables involves in the paper have been discussed in research literatures of human capital, social capital and psychological capital, moreover these survey meters have been proved to be effective and reliable in the relevant literatures.

The human capital meter based on Schultz, Becker's meter, the social capital test meter based on domestic scholar Ke Jianglin's research results, the psychological capital meter uses Luthans PCQ-24 meter ${ }^{[6]}$, Likert 5 point system is used to measure and evaluate for all topics.

\subsection{Research Process}

First of all, software SPSS16 is used to carry out the factor analysis of the twelve factors of athlete growth evaluation from the 559 samples. The purpose of factor analysis is to withdraw the overlapping information parts of the original variables, extract and integrate into the final factors, to reduce the number of variables. Therefore, it requests to have strong correlation in the original variables. Otherwise, if the original variables are independent of each other, there is no information overlap, then they can not be integrated and concentrated, there is no need for factor analysis. In general, we determine if the original variables are suitability to factor analysis through the calculation of the correlation coefficients of original variables, Bartlett's Test of Sphericity and Kaiser-Meyer-Olkin (KMO) test are also can be used.

Table 1 shows the KMO test and Bartlett test results of the original variables. The Approx. Chi-square value of Bartlett's Test of Sphericity is 6.736, significant level (Sig value of 0.000) is less than 0.001. The number indicates that it is the correlation matrix rather than matrix units. KMO coefficient of test sample is 0.851 . According to the KMO metrics Kaiser given, KMO values above 0.9 means factor analysis is very suitable, 0.8 means right suitable. In the study, KMO value of original variables is 0.851 , higher than 0.8 , it illustrates that the correlation matrix of the subject has common factors. Through the test of the two statistical indicators, it indicates that this study was suitable for factor analysis of the data.

\section{Insert Table 1 Here}

To definite factor numbers, there are two methods, the factor characteristic root value and the cumulative variance contribution rate. Table 2 demonstrates the characteristic root value, variance contribution rate, and cumulative variance contribution rate in the three kind situations of initial factor solution, factor solution and final factor solution factor. As shown in Table 2, in the initial factor solution situation, there are three factors whose factorial characteristic root value is bigger than one, its cumulative variance contribution rate is $78.464 \%$. Therefore, it is possible to withdraw three factors to explain the majority of information of original variable, and less information is lost.

\section{Insert Table 2 Here}

Using varimax method to have orthogonal rotation of the factor loading matrix, output the factor loading after rotation in descending order of the first factor loading, the factor loading matrix after rotation is shown in table 3. From table 3, we can see that common prospect, interactive strength, common language, trust and network density have higher load in the first factor. The first factor can explain these variables, in accordance with the relevant research literature, they can be released for the social capita. Optimism, hope, resilience, self-efficacy have higher loading in the second factor. It can explain these variables, they can be summed up as psychological capital. Competition experience, sports skill, knowledge have higher load on the third factor, the main explanation of these three variables can be summed up in human capital. Compared with the previous rotation, the correlation in factors become stronger, and the variables' meaning become clearer.

\section{Insert Table 3 Here}

Table 4 shows the three-factor covariance matrix. It illustrates that there is no linear correlation in the three factors, the design objective of factor analysis have realized.

\section{Insert Table 4 Here}

Using "Cronbach a" coefficient to test on the reliability of the questionnaire (as shown in table 5). The reliability coefficient of variables ranges from $0.764 \sim 0.925$, all are greater than 0.70 , it shows good internal consistency. Therefore, the data obtained through the sample survey is reliable and can be used to further research on the three new variables getting from the factor analysis.

\section{Insert Table 5 Here}




\subsection{Results}

Social capital, psychological capital and human capital all have a significant positive correlation with athlete growth status. For a single capital, the constituent elements all can give a good explanation of the capital value changes.

\section{Conclusion and Suggestion}

In this study, the theoretical derivation and empirical test shows that the three-dimensional model based on human capital, social capital, psychological capital, can explain the growth status of athletes, the three-dimensional capital model constitute the athlete growth evaluation system.

From the economics perspective, the capital concept expands from human capital to social capital and psychological capital. It reflects the expansion of talent's connotation and extension, and talent has higher ability: the disposal of people's own knowledge and skills -- - the disposal of the inter-relationship between people - the disposal of people's positive psychological factor. The talent value should be measured by personnel human capital, social capital and psychological capital. As a kind of highly professional talent, athlete value and growth status also should be measured by human capital, social capital and psychological capital.

Using the three-dimensional capital model to evaluate the athlete growth, we can grasp the athlete developing condition accurately and comprehensively, and then promote the athlete sustainable development. Firstly, we must pay attention to invest to promote the level of athlete's human capital, social capital and psychological capital. Secondly, we should carry on survey of athlete from the three dimensional capitals, obtain the quite accurate comprehensive index by using the science method, attempt to apply it in the athlete selection and training. At the same time, we should try to display the joint effort of athlete three dimensional capitals. Take the athlete human capital as the foundation, display the promoter action fully of athlete social capital and psychological capital, advance athlete's growth and development together.

\section{References}

Fred Luthans, Carolyn M.Youssef \& Bruce J.Avolio. (2008). Translated by Li Chao-ping. Psychological capital: Developing the human competitive edge. Beijing: China Light Industry Press.

Ke, Jianglin, Shi, Jingtao \& Sun Minjian. (2007). Using mathematical models to study research misconduct's affection on national innovation systems. Studies in Science of Science, (5):935-940.

Nahapiet J, Ghoshals. (1998). Social capital, intellectual capital and the organizational advantage. Academy of Management Review, (232):242-26.

Vancouver. Jeffery B. (2002). Two studies examining the negative effect of self-efficacy on performance. Journal of Applied Psychology, Jun. Vol. 87(3):506-516.

Xu, Yan-hui, Zhang, Mei-sheng \& Chen Yang. (2006). Role of Social Capital on Athlete's Cultivation in Liaoning Province. China Sport Science and Technology, (1).

Zhu, Peili. (1993). Revision of the Chinese Norm of the Sports Competition Anxiety Test. Psychological Science, 16(2):99-103.

Table 1. KMO and Bartlett's Test of Sphericity

\begin{tabular}{|lcc|}
\hline$K M O$ coefficient of sample test & 0.851 & \\
\hline \multirow{2}{*}{ Bartlett's Test of Sphericity } & Approx. Chi-square & $6.736 \mathrm{E} 3$ \\
& $\mathrm{df}$ & 66 \\
& Sig. & 0.000 \\
\hline
\end{tabular}


Table 2. Total Variance of the Original Variables in the Factor Analysis

\begin{tabular}{|c|c|c|c|c|c|c|c|c|c|}
\hline \multirow{2}{*}{$\begin{array}{l}\text { Factor } \\
\text { No. }\end{array}$} & \multicolumn{3}{|c|}{ Initial factor solution } & \multicolumn{3}{|c|}{ Factor solution } & \multicolumn{2}{|c|}{ Final factor solution } & \multirow[b]{2}{*}{$\begin{array}{r}\text { Cumulative } \\
\text { variance }\end{array}$} \\
\hline & Characteristic & Variance & $\begin{array}{r}\text { Cumulative } \\
\text { Variance }\end{array}$ & Characteristic & Variance & $\begin{array}{r}\text { Cumulative } \\
\text { variance }\end{array}$ & Characteristic & Variance & \\
\hline 1 & 4.802 & 40.016 & 40.016 & 4.802 & 40.016 & 40.016 & 3.876 & 32.298 & 32.298 \\
\hline 2 & 3.084 & 25.704 & 65.719 & 3.084 & 25.704 & 65.719 & 3.403 & 28.359 & 60.657 \\
\hline 3 & 1.529 & 12.744 & 78.464 & 1.529 & 12.744 & 78.464 & 2.137 & 17.806 & 78.464 \\
\hline 4 & 0.618 & 5.151 & 83.615 & & & & & & \\
\hline 5 & 0.471 & 3.927 & 87.542 & & & & & & \\
\hline 6 & 0.331 & 2.762 & 90.304 & & & & & & \\
\hline 7 & 0.289 & 2.407 & 92.711 & & & & & & \\
\hline 8 & 0.252 & 2.100 & 94.811 & & & & & & \\
\hline 9 & 0.211 & 1.758 & 96.568 & & & & & & \\
\hline 10 & 0.178 & 1.487 & 98.055 & & & & & & \\
\hline 11 & 0.124 & 1.036 & 99.091 & & & & & & \\
\hline 12 & p.109 & 0.909 & 100.000 & & & & & & \\
\hline
\end{tabular}

Table 3. Factor Loading Matrix after Rotation

\begin{tabular}{|lcccc|}
\hline \multirow{2}{*}{ Indicator variables } & & \multicolumn{3}{c|}{ Factor } \\
\cline { 3 - 5 } & & 1 & 2 & 3 \\
\hline \multirow{3}{*}{ Social Capital } & Common prospect & 0.905 & -0.264 & 0.025 \\
& Interactive strength & 0.881 & -0.033 & 0.201 \\
& Common language & 0.863 & 0.018 & 0.215 \\
& trust & 0.847 & -0.362 & 0.047 \\
& Network density & 0.790 & -0.146 & -0.018 \\
\hline \multirow{3}{*}{ Psychological Capital } & Optimistic & -0.114 & 0.922 & 0.087 \\
& Hope & -0.148 & 0.897 & 0.120 \\
& Resilience & -0.133 & 0.875 & 0.041 \\
& Self-efficacy & -0.162 & 0.852 & 0.015 \\
\hline \multirow{3}{*}{ Human Capital } & Game experience & 0.210 & 0.119 & 0.865 \\
& Sports skill & 0.251 & 0.139 & 0.822 \\
& Knowledge & -0.088 & -0.026 & 0.774 \\
\hline
\end{tabular}

Table 4. Factor Covariance Matrix

\begin{tabular}{|llll|}
\hline Factor & 1 & 2 & 3 \\
\hline 1 & 1.000 & 0.000 & 0.000 \\
2 & 0.000 & 1.000 & 0.000 \\
3 & 0.000 & 0.000 & 1.000 \\
\hline
\end{tabular}


Table 5. Reliability Test of Factor Analysis

\begin{tabular}{|llll|}
\hline Factor variables & Mean & Correlation coefficient & Alpha coefficient \\
\hline Social capital & 3.937 & 0.714 & 0.925 \\
Psychological capital & 4.314 & 0.751 & 0.924 \\
Human capital & 3.469 & 0.546 & 0.764 \\
\hline
\end{tabular}

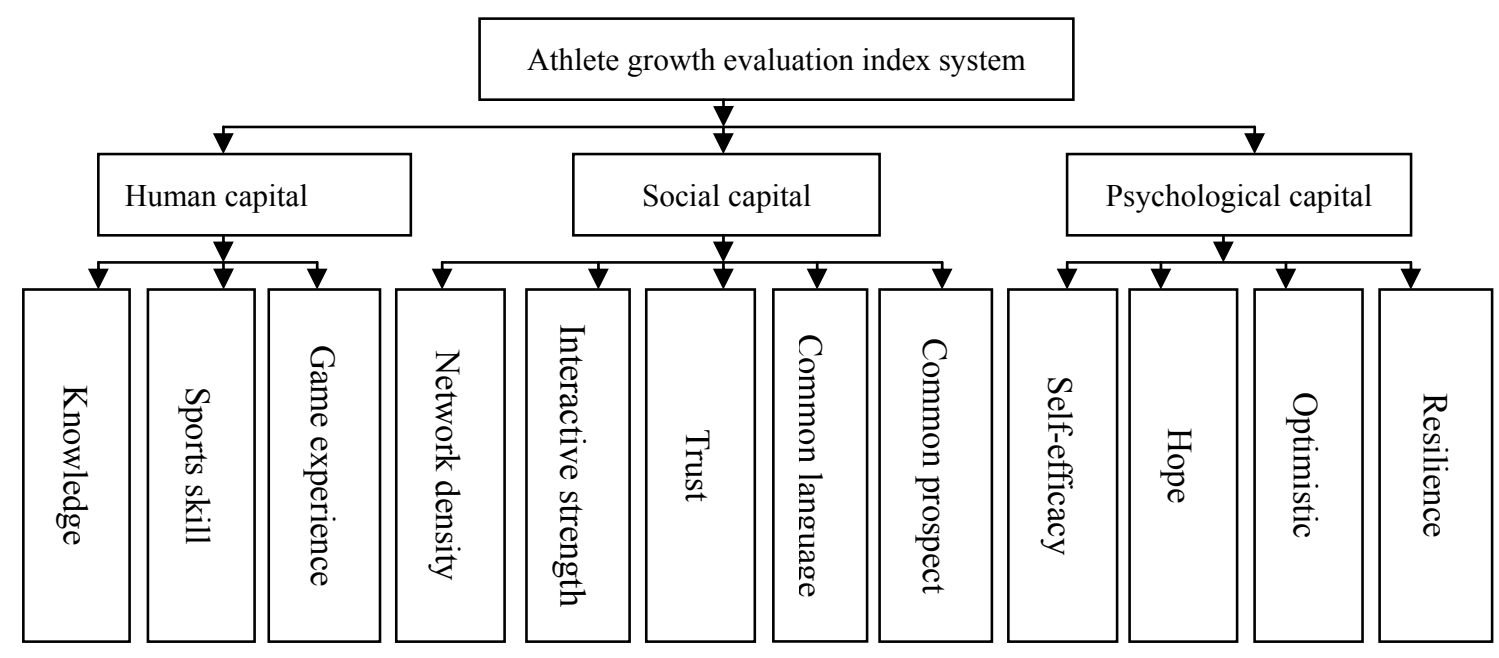

Figure 1. Athletes growth evaluation index system 